\section{SOCIABILIDAD CULTURAL, PERIODISMO Y MOVILIZACIÓN EN EL SOCIALISMO ARGENTINO: LA CASA DEL PUEBLO DE BUENOS AIRES, 1927-1953}

CULTURAL SOCIABILITY, JOURNALISM AND MOBILIZATION IN ARGENTINE SOCIALISM: THE CASA DEL PUEBLO OF BUENOS AIRES, 1927-1953

\section{JUAN BUONUOME .}

Investigador Asistente del CONICET con sede en el Centro de Estudios de Historia Política, Escuela de Política y Gobierno de la Universidad Nacional de San Martín.

E-mail: jbuonuome@unsam.edu.ar

\section{Resumen}

El artículo analiza la historia de la Casa del Pueblo, epicentro de la sociabilidad política y cultural del Partido Socialista en la ciudad de Buenos Aires durante las décadas de 1930 y 1940. trabajo se interesa por el cruce entre sociabilidad política y periodismo desde la perspectiva que ofrece La Vanguardia, cuyos talleres y oficinas de redacción ocupaban buena parte del edificio. Examina los usos de la Casa del Pueblo en el contexto de entrelazamiento entre la vida política y la cultura de masas del período. Para ello, analiza el rol cultural que cumplió al combinar las modalidades del ateneo, de la universidad popular y del club social, y aborda las formas de movilización y uso político de la calle que se desplegaron en torno suyo.

\section{Registro bibliográfico}

BUONUOME, JUAN «Sociabilidad cultural, periodismo y movilización en el socialismo argentino: la Casa del Pueblo de Buenos Aires, 1927-1953», en: ESTUDIOS SOCIALES, revista universitaria semestral, año XXVIII, $n^{\circ}$ 55, Santa Fe, Argentina, Universidad Nacional del Litoral, julio-diciembre, 2018, pp. 199-224.

\section{Abstract}

The article studies the history of the Casa del Pueb/o, epicenter of the political and cultural sociability of the Socialist Party in the city of Buenos Aires during the 1930s and 1940s. One of the interests of the work is the crossing between political sociability and journalism, from the perspective offered by La Vanguardia, whose workshops and editorial offices occupied a large part of the building. Examines the uses of the Casa del Pueblo in the context of the entanglement between political life and the mass culture of this period. To do this, it analyzes the cultural role played combining the modalities of the athenaeum, the popular university and the social club, and addresses the forms of mobilization and political use of the street that were deployed around the building.

\section{Descriptores · Describers}

Socialismo / Sociabilidad / Periodismo / Movilización / Cultura de Masas

Socialism / Sociability / Journalism / Mobilization / Mass Culture

Recibido: 12 / 03 / 2018 Aprobado: 20/06/2018 
Al echar una mirada sobre la historia del socialismo en la Argentina, resulta un lugar común afirmar que la irrupción del peronismo a mediados de los años 1940 representó un verdadero final de época. El Partido Socialista (PS) sufrió entonces la pérdida absoluta de representación parlamentaria, un sensible declive en su influjo dentro del movimiento sindical y la agudización de tensiones internas, que derivaron en alejamientos y expulsiones de destacados dirigentes. Es verdad que, como ha advertido Carlos Herrera recientemente, el ascenso de Perón no debe ser visto como el origen de la crisis socialista, cuyas raíces se pueden rastrear en la década precedente. No obstante, «si el peronismo no es la causa de la crisis que vivirá el Partido Socialista, representa con todo su acmé» (HERRERA, 20I6: XVII). Por esa razón, probablemente, el declive de mediados de siglo del socialismo suele ilustrarse con la referencia a dos episodios que aluden al impacto material y directo que tuvo el peronismo sobre el epicentro de la sociabilidad política y cultural del partido: la Casa del Pueblo.

El primero, sucedido en agosto de 1947, fue la clausura de los talleres tipográficos de la Sociedad Editora "La Vanguardia», donde se elaboraba el órgano central de prensa del partido, además de múltiples materiales impresos vinculados al movimiento obrero y socialista. Ejecutada a través de mecanismos burocráticos, esta decisión fue relevante, entre otras cosas, porque produjo la virtual desaparición de la voz socialista en el seno de la opinión pública periodística. El segundo episodio, acontecido en abril de 1953 , fue el incendio intencional de la sede central del ps por parte de simpatizantes peronistas. Iniciado en represalia por un brutal atentado durante un acto oficialista realizado esa misma tarde, el fuego destruyó por completo las oficinas y salones donde transcurrían las actividades partidarias, además del grueso de los materiales de la biblioteca que funcionaba en su interior.

Si bien la preocupación por profundizar en la experiencia cultural socialista ha caracterizado a la expansión de estudios de los últimos años sobre esta fuerza, poco se sabe sobre los usos y representaciones a que dio lugar este edificio. El presente trabajo busca saldar este vacío. Para ello, hace de la Casa del Pueblo de Buenos Aires el prisma desde el cual observar los puentes entre la vida cultural del socialismo argentino y el proceso más amplio de transformaciones de las prácticas culturales y políticas de los años I930 y I940.

Ya desde fines del siglo xIx, los socialistas contaban con un ámbito físico de organización y reafirmación identitaria que aglutinaba un haz de actividades políticas y culturales con propósitos y públicos diversos. No obstante, la inaugu- 
ración en 1927 de la Casa del Pueblo significó un verdadero hito ya que proyectó al socialismo en el espacio público de la ciudad y le brindó una plataforma material y simbólica de reconocimiento y gravitación en su vínculo con otros actores políticos y sociales. Si bien su inauguración se produjo en un momento crítico para esta fuerza política, pues coincidió con la muerte de su líder Juan B. Justo, con la división de un sector importante del partido y con dos derrotas electorales a manos del sector escindido, los años 1930 estuvieron lejos de significar un período de decadencia que anticipaba la «crisis peronista». En cambio, el socialismo atravesó en estos años un movimiento ascendente, sostenido por la ampliación de su representación parlamentaria producto de la abstención del radicalismo, la dirección de las organizaciones obreras, la incorporación de núcleos de militantes juveniles y una exitosa instrumentalización de la prédica antifascista. Aunque estos cambios provocaron la reaparición de viejas tensiones y dilemas, el socialismo de los años 1930 y principios de los 1940 se posicionó como actor destacado de la vida política argentina (MARTÍNEZ MAZZOLA, 20I7). En este sentido, registrar los usos materiales y simbólicos de la Casa del Pueblo ofrece la posibilidad de profundizar en la vitalidad socialista desde un punto de vista cultural.

El artículo parte de un recorrido por algunos antecedentes socialistas de la Casa del Pueblo y de un rastreo por las alternativas políticas y financieras del proyecto hasta su concreción. Una de las marcas distintivas de la experiencia local estuvo vinculada a la importancia que adquirió la función periodística y editorial en el origen y funcionamiento de la Casa del Pueblo. Esta hipótesis es puesta a prueba en el segundo apartado, donde se analiza el cruce entre sociabilidad política y periodismo desde la perspectiva que ofrece La Vanguardia, órgano partidario cuyos talleres y oficinas de redacción ocupaban buena parte del edificio. A continuación, el trabajo se interesa por el rol cultural que cumplió la Casa del Pueblo al alternar y combinar los objetivos y modalidades del ateneo, de la universidad popular y del club social. Finalmente, en el cuarto apartado, se consideran las formas de movilización y uso político de la calle que se desplegaron en torno a la Casa del Pueblo. Estas últimas secciones se sostienen sobre una premisa: si bien el socialismo desplegó un accionar marcado por un sesgo fuertemente pedagógico, sus iniciativas y prácticas culturales no pueden ser analizadas sin tener en cuenta la incidencia que tenían las novedades de la cultura de masas en la vida política del período. En las conclusiones se realiza un balance sobre lo analizado en el texto y se reflexiona sobre el impacto que tuvo la irrupción del peronismo sobre la cultura política de los socialistas. 


\section{CASA DEL PUEBLO, MODELO PARA ARMAR}

Desde fines del siglo XIx la socialdemocracia europea impulsó el uso de locales que funcionaran como espacios de socialización política de la clase trabajadora, a los que llamó «casas del pueblo». Financiadas por cooperativas obreras y sociedad mutuales y, por lo tanto, orientadas en un comienzo a una función económica y social, las casas del pueblo creadas por el movimiento socialista se diferenciaron de los ámbitos tradicionales de solidaridad y cooperación proletarias por el mayor peso que pasaron a tener las actividades e iniciativas culturales y políticas (COSSART Y TALPIN, 2OI2; DE LUIS MARTÍN y GONZÁlEZ ARIAS, 2009). Con la consolidación de la socialdemocracia a comienzos de siglo xx, las principales capitales de Europa contaron con casas del pueblo más grandes y ambiciosas en términos arquitectónicos que permitieron satisfacer mayor cantidad de funciones y alteraron el paisaje simbólico de las ciudades al dotar al movimiento socialista de una potente referencia espacial (BRAUMAN y CULOT, I984; KOHN, 2OOI).

Hijo de la Segunda Internacional, el ps de Argentina adoptó a las casas del pueblo como uno de sus vehículos de construcción política. Desde sus orígenes sus miembros discutieron e impulsaron diversos proyectos tendientes a replicar las iniciativas exitosas observadas en Europa. Las experiencias de sus pares en Bélgica y España solían captar particularmente su atención. La imponente Maison du Peuple de Bruselas fue, en realidad, un ejemplo a seguir para toda la socialdemocracia internacional. Diseñada por el arquitecto modernista Víctor Horta, fue inaugurada en 1899 bajo el auspicio del Partido Obrero Belga y su potente movimiento cooperativo (DELHAYE, I987). En I895 Juan B. Justo conoció de primera mano los establecimientos cooperativos del socialismo belga y en 1903 Adrián Patroni visitó las instalaciones de la Maison du Peuple, de la cual dejó crónicas detalladas. En I928 y en 1939, fueron Mario Bravo y Juan A. Solari, respectivamente, los que se deslumbraron con la casa de los socialistas belgas. En tanto, un estrecho y permanente contacto con sus pares españoles hizo que sus casas del pueblo fueran observadas con mucha atención por los argentinos.

De todas maneras, existen algunos rasgos peculiares para el caso argentino. En primer lugar, el local de la Capital Federal asumió un peso material y simbólico desproporcionado con relación a las casas del pueblo del país. Este rasgo, ligado a la centralización política y organizativa del socialismo argentino, se puede rastrear 
en forma temprana ${ }^{1}$. Es verdad que, con la extensión territorial del socialismo y su penetración en poblaciones del litoral y el interior a comienzos del siglo xx, comenzaron a florecer numerosas casas del pueblo. No obstante, el local de la ciudad de Buenos Aires, donde residían los organismos de dirección nacional del partido, asumió un grado de representatividad mucho mayor que las sedes centrales de la socialdemocracia en Europa, donde pesaban más las disparidades regionales y la mayor autonomía local de los componentes del movimiento obrero socialista. A tal punto que en los años I930 será usual encontrar en la prensa y el debate público el uso del término «casa del pueblo» como sinónimo de socialismo argentino.

Ello se encuentra ligado a un segundo rasgo distintivo del caso argentino: la débil incidencia de las organizaciones obreras y cooperativas en la creación de las casas del pueblo, fruto del predominio de la acción electoral y parlamentaria. El partido fue el factor determinante y las iniciativas impulsadas por dirigentes a principios de siglo xx para darle un rol preponderante a las sociedades obreras en la construcción de una gran casa del pueblo resultaron en fracaso. Así sucedió con las propuestas de Adrián Patroni y Alfredo Torcelli en 1905 que procuraban erigir un gran local para dar cobijo a la Cámara del Trabajo y a la Unión General de Trabajadores. De hecho, tras la expulsión del sector sindicalista con el que Torcelli tenía un vínculo estrecho, y después de la partida de Patroni del ps, la sociedad que habían constituido con el nombre «Casa del Pueblo» fue disuelta y el dinero reunido fue utilizado para capitalizar la iniciativa cooperativa que Justo y algunos dirigentes fundaron ese mismo año con el nombre de «El Hogar Obrero» (BALlent, 20I4). Tres años después, a iniciativa de Enrique Dickmann, la idea de construcción de una gran casa propia será retomada, aunque la acción cooperativa no fue lo fundamental, sino la necesidad de dotar a las tareas de redacción e impresión del órgano central de prensa del partido de un espacio propio y adecuado.

La importancia otorgada a la actividad periodística y editorial en la construcción de un gran espacio de sociabilidad es el tercer rasgo que singulariza al socialismo argentino, que se deriva del rol estratégico asumido por La Vanguardia, órgano central de prensa del Ps, tanto para coordinar y disciplinar a los distintos componentes del movimiento socialista como para interpelar a sectores más amplios de la sociedad (BUONUOME, 20I5). Desde sus primeros pasos la actividad periodística, y La Vanguardia en particular, había sido clave para apuntalar la formación y con-

\footnotetext{
1 «Algo práctico. Un gran local obrero», La Vanguardia (LV), 04/08/1894.
} 
solidación del ps. Los primeros locales utilizados para la confección del periódico (desde i894) proporcionaron el ámbito que permitió la reunión de los distintos clubes y asociaciones. Hacia I899, los socialistas argentinos llegaron a contar con una casa propia, que daba cobijo al periódico, al Comité Ejecutivo del Partido y a distintas entidades culturales y gremiales. Algunos se refirieron a este local de la calle México 2070 como la "pequeña casa del pueblo», en alusión a la recientemente inaugurada de Bruselas (BUONUOME, 20I7). Pero en aquel imponente "palacio» socialista belga, y en la más modesta Casa del Pueblo de Madrid, la actividad periodística y editorial no cumplían ningún papel. En cambio, en una ciudad como Buenos Aires, donde los diarios cumplían un rol fundamental como espacios de interacción social, no es casual que los socialistas hayan estructurado su sociabilidad política y cultural en función de la actividad periodística y editorial (ROMÁN, 2OIO). A tal punto, que los traslados que debieron realizar en I905 y en I9I3 estuvieron motivados por las sucesivas modernizaciones del diario; con la ampliación de los talleres y la incorporación de nuevo personal de redacción, los socialistas debieron alquilar locales que ofrecían los requerimientos mínimos para el despliegue de la función periodística, aunque con limitadas posibilidades para desarrollo del resto de las actividades partidarias.

Distintos factores operaron para que el proyecto de construcción de una gran casa propia se viera postergado. Por una parte, debe señalarse la escasez de recursos: después de las pérdidas generadas por el asalto sufrido durante las celebraciones del Centenario, tuvo prioridad la modernización de La Vanguardia como forma de capitalizar los éxitos electorales de I9I2 y I913. Luego, los efectos económicos de la guerra mundial alejaron la posibilidad de motorizar el emprendimiento. Por otra parte, debe mencionarse la situación interna del partido, atravesada por la emergencia de una tendencia de izquierda que cuestionaba la gestión de la producción y la propiedad de los bienes del partido bajo la forma de una sociedad anónima (BUONUOME, 20I6). Recién en I9I8, tras la expulsión de los impugnadores de la línea dominante del ps, y en el marco de una tibia recuperación económica, se reimpulsó el proyecto. El período transcurrido hasta su inauguración en 1927 estuvo marcado, por una parte, por la sustancial mejora en los índices económicos y de bienestar popular; y, por otra parte, por la aparición de una nueva disidencia que, antes que demorar el proyecto, fue fundamental para llevarlo adelante. 
El costo total de la construcción de la Casa del Pueblo rondó los 800.000 pesos. Si bien el financiamiento provino de diversas fuentes -crédito bancario, suscripción pública, dietas parlamentarias, fiestas a beneficio, préstamos y donaciones de afiliados- fue fundamental el papel cumplido por un grupo de industriales y comerciantes medianos ligados al partido. En un contexto de reactivación económica, los aportes de estos socialistas prósperos fueron clave para poner en marcha el proyecto. El más destacado fue José Iturrat, empresario de ascendencia vasca, propietario de una fábrica de sobres y de varias casas de comercio, que donó 80.000 pesos en I9I8 que fueron fundamentales para el inicio de las operaciones de la comisión "pro Casa»".

Por otra parte, fue evidente desde el inicio el peso que asumió el grupo de dirigentes que en 1927 rompió con el partido y formó el Partido Socialista Independiente (PSI). Si bien no tuvieron un rol clave en el financiamiento -como sí lo tuvo Nicolás Repetto, que prestó 70.000 pesos libres de interés- estuvieron involucrados directamente en la realización del proyecto ${ }^{3}$. Quien tuvo el rol más destacado fue Alfredo L. Spinetto. Presidente del Concejo Deliberante de la Capital Federal desde 1918 e hijo del dueño del mercado mayorista que llevaba su nombre ubicado en la zona de Congreso, Spinetto lideró las gestiones por la adquisición del terreno y por la licitación del proyecto. También tuvo un papel relevante Raúl Carballo, quien alternó sus funciones como diputado nacional por Córdoba con su labor como ingeniero civil a cargo de la obra, mientras que los planos fueron inicialmente solicitados a Jorge Bunge, hermano del dirigente socialista (después miembro del PSI) Augusto Bunge, aunque luego fueron rechazados y encargados al arquitecto italiano Pedro R. Carmona. Finalmente, Antonio De Tomaso, el dirigente más representativo del sector disidente, tuvo su rol: desde su estudio de abogados pudo acelerar el pedido de personería jurídica solicitado para la Sociedad Editora «La Vanguardia» y vinculó a ella la propiedad del nuevo inmueble.

\footnotetext{
2 José Iturrat había hecho su fortuna en el negocio del retorno de papel, en estrecha vinculación con la familia Paz, propietaria de La Prensa. Iturrat participó además del «Comité Juan A. Luoni», que se encargó de recaudar fondos para pagar la deuda de 240.000 pesos contraída por el PS con el Banco «El Hogar Argentino». "Comité Juan A. Luoni», LV, 13/05/1928; "Casa del Pueblo», LV, 14/09/1930. 3 Nicolas Repetto, «La reforma de los Estatutos. La S.A. La Vanguardia y la Comisión de Prensa», 02/07/1958, Fondo Juan Antonio Solari, CeDinCi.
} 


\section{LA CASA DE PAPEL}

Si bien la Casa del Pueblo fue pensada como un lugar con diferentes sentidos y funciones, su condición de sede del periódico partidario fue una de sus facetas más destacadas. Ello se vinculaba menos a los usos del movimiento socialista internacional que al rol que tenían los periódicos en la configuración y en las dinámicas del espacio público local. A fines del siglo xix, en el contexto de las transformaciones que atravesaba la ciudad de Buenos Aires, importantes segmentos estudiantiles, profesionales, gremiales e intelectuales se nuclearon en torno a las casas de los diarios (Gómez, 2008). La Prensa fue el primer diario cuyo edificio fue construido pensando en su uso público: en su "palacio» de Avenida de Mayo, inaugurado en 1898 , se dispusieron salas que ofrecían servicios gratuitos destinados a diferentes necesidades del público urbano. A su vez, contaba con un gran hall de entrada que servía de punto de reunión e información cuando se producía algún acontecimiento nacional o internacional relevante, o cuando estallaban movimientos de opinión que derivaban en manifestaciones callejeras de protesta frente los poderes públicos, emplazados a pocas cuadras (ROJKIND, 2OI2). Vespertinos exitosos como La Razón y Crítica, replicaron en las décadas siguientes estas prácticas, que se correspondían con una noción moderna de la actividad periodística, según la cual los órganos de prensa debían asumir el rol de vehículo privilegiado de la opinión pública. La expresión de los verdaderos intereses colectivos requería de la existencia de un espacio físico que actuara como receptor y amplificador de las demandas del "pueblo».

Que el socialismo argentino debió erigir su centro de sociabilidad política y cultural sobre la base de un juego de espejos respecto a estas experiencias periodísticas locales, lo prueba el hecho de que la misma expresión «Casa del Pueblo» fue apropiada con éxito por los representantes de la "prensa burguesa», como La Prensa y La Razón (BUONUOME, 2017; Gómez, 2008: 273). Ello no puede extrañar, ya que, debido a sus estrategias de vinculación con los lectores basadas en la fidelidad y la confianza, los salones y oficinas de estos periódicos veían desfilar a miembros del «pueblo trabajador» que encontraban allí un espacio donde exponer sus problemas y penurias cotidianas (SAÍTTA, I998: I3O-I32). Es sintomático que la edificación de la Casa del Pueblo del ps se produjera entre 1925 y 1927, en perfecta sincronía con la construcción del publicitado edificio del diario Crítica de Avenida de Mayo.

Pero más allá de la familiaridad entre las prácticas generadas en torno a los edificios de la gran prensa porteńa y la sociabilidad desplegada en la sede del ps y 
su órgano central, es necesario destacar una diferencia importante. Mientras que La Prensa, La Razón y Crítica propiciaron un uso público de sus instalaciones, en función de su voluntad por erigirse en los «verdaderos» representantes de la opinión mayoritaria, los socialistas se encargaron de señalar que la Casa del Pueblo no servía al conjunto de la masa trabajadora, sino tan sólo al sector más esclarecido. Cuando Juan B. Justo tomó la palabra durante su fiesta de inauguración indicó que el ps no pretendía ser «una institución pública», de allí que el edificio se denominara Casa del Pueblo, y no «La» Casa del Pueblo. A pesar de sostener una retórica inclusiva fundada en el lenguaje de «lo popular» (que llevó a rechazar la propuesta de Antonio De Tomaso para denominarla "Casa del Partido»), su función primordial sería servir sólo a «la parte políticamente más consciente del pueblo», que desde allí debía irradiar sentimientos e ideas sociales hacia el resto del pueblo ${ }^{4}$.

Ubicada en Rivadavia 2150, entre Rincón y Pasco, la Casa del Pueblo se hallaba a mitad de camino entre el eje cívico de la ciudad (a poco más de tres cuadras de la plaza de los dos Congresos) y uno de sus núcleos comerciales y productivos (a cinco cuadras de Plaza Once y a tres del mercado Spinetto). Construido sobre un terreno donde antes había un taller metalúrgico, el edificio contaba de una planta baja, dos pisos altos y un subsuelo. En total, sumaba un poco menos de 2000 metro cuadrados cubiertos ${ }^{5}$. En la planta baja se encontraban la librería y las oficinas de redacción, secretaría y administración de La Vanguardia. Además, había allí un gran hall, con una escalera de mármol blanco a dos alas, una de las cuales llevaba a los pisos superiores y la otra al sótano. En el primer piso se hallaban el gran salón de actos, el café-comedor y la biblioteca. En el segundo piso se ubicaban los locales del Comité Ejecutivo del ps y la Junta de la Capital, como así también las oficinas de El Hogar Obrero y de algunas entidades partidarias y gremiales. En el sótano, se hallaban las rotativas del diario, el salón de estereotipia y linotipia, y el depósito de bobinas. También contaba el edificio con una terraza utilizada para actividades al aire libre y donde había un pequeño cuarto para la hemeroteca.

Una parte importante de la superficie del edificio estaba dedicada al funcionamiento de La Vanguardia. Esteban Dagnino, un integrante «histórico» de su redacción, reflexionaba sobre la relevancia de la nueva casa para la vida del periódico: dado que «un diario moderno es esencialmente un organismo delicado

\footnotetext{
4 "Inauguración de la Casa del Pueblo», LV, 24/01/1927.

5 "La Casa del Pueblo. Sociedad Editora La Vanguardia», El Arquitecto Constructor, 01/02/1927.
} 
y complejo, en el que desempeña un papel importantísimo la descentralización de sus múltiples servicios» -escribía- la Casa del Pueblo redundaba en «ventajas inapreciables para la buena marcha del diario ${ }^{6}$. En efecto, la posibilidad de contar con nueve oficinas separadas para las distintas labores de redacción y administración del periódico, permitía una división de tareas mucho mayor a la que había podido aspirar hasta entonces. También Justo destacaba la importancia de la nueva casa para las necesidades del diario. Según él, el partido era, ante todo, un «organismo de trabajo social», un «taller», una «escuela de trabajo político». De allí que se felicitara de que la redacción de La Vanguardia se viera favorecida ahora con piezas separadas, silenciosas y austeras, para el estudio y la meditación, y también de que las labores de impresión y composición contaran ahora con un «vasto y pulcro recinto» 7 .

En realidad, en esta «casa-taller» no sólo se componía e imprimía el órgano del partido sino también una formidable cantidad de periódicos, revistas, libros y folletos, muchos de los cuales bajo el sello editorial «La Vanguardia». Desde esta plataforma, el socialismo argentino desplegó una robusta política editorial que incluyó un conjunto diverso de materiales de lectura, de autores locales e internacionales ${ }^{8}$. A su vez, la imprenta de la Casa del Pueblo funcionaba como un emprendimiento meramente comercial, al realizar trabajos de impresión y fotograbado que redituaban no pocos ingresos a las arcas socialistas. En efecto, a principios de la década de 1930, bajo la administración de Rómulo Bogliolo, la Sociedad Editora "La Vanguardia», de la que dependían el diario, el taller de obras y la librería, no parecía sentir el rigor de la crisis económica: estaba al día con sus gastos corrientes, devolvía sus deudas, adquiría una nueva rotativa e incluso cubría parte de los gastos del Comité Ejecutivo del ps, que sufría entonces un déficit en sus cuentas?

A pesar de tratarse de una empresa de cierta envergadura -en sus talleres de imprenta trabajaban diariamente sesenta personas-, la administración nunca debió enfrentar conflictos laborales de magnitud. Se trataba de una cuestión crucial. No sólo por la contradicción que hubiese significado respecto de la condición militante

${ }^{6}$ Esteban Dagnino, «La nueva casa», LV, 01/01/1927.

7 «Inauguración de la Casa del Pueblo», LV, 24/01/1927.

${ }^{8} \mathrm{Al}$ respecto, consultar el artículo de Ricardo Martínez Mazzola de este mismo dossier.

9 «Informe de Administración», en: XXI CONGRESO ORDINARIO DEL PARTIDO SOCIALISTA (1932: 70-71). 
de la empresa. Además, los socialistas habían puesto mucho empeño en denunciar la explotación y los atropellos que sufrían los obreros gráficos en las dependencias de La Prensa, en los talleres del diario La Razón y en el diario Crítica a mediados de los años 1920. Para sostener esta posición y evitar el bochorno, no era suficiente reafirmar el carácter socialista del emprendimiento y el apego a los reglamentos de la Federación Gráfica Bonaerense. La administración tenía perfecta consciencia respecto del rol que cumplía como empleadora: Nicolás Repetto, en su carácter de presidente de la sociedad anónima, afirmaba en un congreso partidario que «a veces hay que hacer el papel de patrón, porque no siempre el personal comprende que trabaja en una empresa impersonal (...) Los tiempos han cambiado y por lo mismo es necesario implantar las normas administrativas que rigen en las empresas privadas $»^{10}$. Pero quienes estaban a cargo de gestionar no rehuían a prácticas paternalistas muy comunes en el mundo de la "prensa burguesa», eficaces a la hora de minimizar la conflictividad laboral. Así, eran frecuentes las fiestas de camaradería y agasajos que reunían a los miembros de la dirección, la administración y al personal de la imprenta, donde se recreaba un espíritu de solidaridad y comunión, como así también la costumbre de incluir a los regentes de los talleres como oradores en los actos importantes relativos al devenir del diario.

La Casa del Pueblo solía recibir la visita de personas para las cuales el diario La Vanguardia cumplía un papel importante, aquellos que buscaban que el diario recogiera sus reclamos y los amplificara en sus páginas. Esta práctica no era novedosa. Ya a comienzos de siglo, la redacción de La Vanguardia podía atender a un grupo de estudiantes del Colegio Nacional en huelga de protesta contra su profesor de matemática, o a un «ciudadano simpatizante del socialismo» que denunciaba los atentados que había sufrido en manos de un «joven malevo» ${ }^{11}$. Tras la inauguración de la Casa del Pueblo en 1927, se hizo costumbre que los visitantes, tras ser recibidos por los miembros de la redacción, se tomaran una fotografía en las escalinatas del hall central, que luego se publicaba junto a la nota. Dado que las visitas eran en su abrumadora mayoría realizadas por comitivas gremiales, el ritual fotográfico permitía a La Vanguardia exhibir cercanía e intimidad con los

10 «XX Congreso Ordinario del Partido Socialista, 1929», La Vanguardia, 11/10/1929.

11 «Los estudiantes del Nacional en huelga contra el profesor de Matemáticas», LV, 24/05/1907; LV, 21/04/1908. 
trabajadores organizados, en un período en el que, a pesar del peso ganado por el socialismo en la dirección de los organismos sindicales, su identidad como «partido obrero» se hallaba más cuestionada que nunca. En paralelo al énfasis que el periódico brindaba a la prédica antifascista -eficaz a la hora de interpelar a sectores medios «independientes»-, las visitas a su redacción más promocionadas no fueron ya las de estudiantes y «ciudadanos», sino las de obreros ferroviarios, portuarios y textiles que agradecían el papel de La Vanguardia a la hora de defender sus derechos ${ }^{12}$.

\section{SOCIABILIDAD CULTURAL Y POLÍTICA}

Durante las décadas de 1920 y 1930, la estructura organizativa de los principales partidos que competían en la ciudad de Buenos Aires se vinculó en forma estrecha con las prácticas de sociabilidad popular y uso del tiempo libre. El aporte del socialismo a este proceso fue fundamental: según el mandato reformista de pedagogía ciudadana, sus esfuerzos estuvieron orientados a una tarea específicamente cultural, convencidos de que la emancipación prioritaria de los obreros era la de la ignorancia ${ }^{13}$. Las bibliotecas, las conferencias educativas, los cursos de formación, los festivales, entre otras actividades, fueron los medios que ensayaron los socialistas para lograr una inserción territorial permanente en el espacio social urbano (BARRANCOS, I99I). Los comités radicales, en cambio, pusieron mayor esfuerzo en facilitar el encuentro con los vecinos a partir de la atención de sus necesidades médicas, alimentarias y de asesoramiento legal, y recién en la segunda mitad de la década del treinta, se volcaron a una campaña político-cultural mediante la creación de bibliotecas, la organización de conferencias y la publicación de revistas (DE PRIVITELLIO, 2003).

Estos esfuerzos expresaban el resultado de un proceso general de imbricación entre sociabilidad cultural y política durante la década de I930 (BISSO, 2009). Distintos agrupamientos hacían de las iniciativas de ocio y recreación mecanismos de politización. La maduración de un público consumidor de formas masivas de ocio y entretenimiento ofrecía más chances para la exploración de iniciativas como

12 «Aplauden a La Vanguardia ferroviarios de Escalada», LV, 05/04/1939; "Delegación obrera en La Vanguardia», LV, 01/08/1939; "Demostración de obreros textiles a nuestro diario», LV, 08/04/1944

13 «Treinta años de acción cultural del Partido Socialista», LV, 28/06/1926, 
la proyección cinematográfica, los bailes, los conciertos, los torneos de fútbol, las excursiones. El lugar que le cupo al socialismo en este proceso fue decisivo. Junto con la insistencia en la importancia de la instrucción elemental, la enseñanza técnica y la divulgación científica, el ps apostó a reformar las costumbres de las mayorías a través de iniciativas lúdicas o festivas (BIsso, 2009; GUIAMET, 20I7). Desde su inauguración, la Casa del Pueblo funcionó como condensación, articulación e inspiración del aparato cultural socialista y en sus salones, transitados por un público muy diverso y ávido, se palpitaron las tensiones entre el ideal pedagógico del iluminismo y los nuevos lenguajes de la cultura de masas.

La biblioteca de la Casa del Pueblo constituía uno de sus principales focos de interés cultural. En realidad, la «Biblioteca Obrera» no pertenecía formalmente al partido: fundada en 1897 por el Centro Socialista de Estudios y con personería jurídica desde 1913 , fue trasladada en 1927 al primer piso de la nueva casa. Al momento de la mudanza, su director era Ángel Giménez, también director y principal inspirador de la Universidad Popular Sociedad Luz. Caracterizado por Américo Ghioldi como «uno de los más decididos pioneers de la extensión universitaria», Giménez había puesto un gran empeño desde los años i89o en el impulso a las conferencias científicas y en la formación de bibliotecas en centros y ateneos socialistas (GIMÉNEZ, I932).

Abierta todos los días hábiles de I4 a 2I horas y los sábados de I4 a 22, la sala de lectura de la biblioteca recibía, en promedio, entre cincuenta y ochenta personas cada día, y para fines de los años 1930 y principios de los años 1940, este número ascendía a 150 o 200 personas. Las preferencias de los lectores se volcaban a las obras catalogadas como «literatura», lo que indica una preferencia por la lectura recreativa, aunque también eran importantes las «ciencias puras» e "historia y geografía». El volumen del acervo bibliográfico era significativo: de 20.000 títulos a fines de los años 1920, pasó a 90.000 a principios de los años 1950, a lo que debe agregarse una importante cantidad de colecciones de periódicos. La Biblioteca Obrera suele considerarse el emblema de la labor cultural de la Casa del Pueblo, probablemente por las fuertes connotaciones anti totalitarias que la imagen de la quema del reservorio bibliográfico y hemerográfico en abril de 1953 dejó en la memoria. Pero no es la Biblioteca el factor que explica mejor por qué la Casa del Pueblo opacó a otras instituciones socialistas dedicadas a la cultura. De forma similar a la Sociedad Luz, anclada en concepciones higienistas y normativas propias del cambio de siglo, la Biblioteca parece haber sostenido a lo largo del 
tiempo una sociabilidad más bien tradicional, al menos desde el punto de vista de género: en enero de 1940, de las I529 personas que acudieron a su sala de lectura, sólo 99 eran mujeres ${ }^{14}$.

Las actividades organizadas en el salón de actos y en la terraza del edificio de Rivadavia, en cambio, mostraron una cara más novedosa vinculada al peso de lo lúdico y a una capacidad de convocatoria más amplia y diversa, que incluía a las mujeres, a los jóvenes y a los niños. Prácticamente todos los días la Casa del Pueblo ofrecía una actividad, fuera festival, acto, baile, conferencia, exhibición, proyección, concierto, velada, té o muestra de arte. Los festivales artísticos y danzantes eran los más concurridos. Se trataba de veladas de estilo varieté, compuestas de distintas secciones: orquesta, recitación, conferencia, proyección de films, entrega de premios y un gran baile familiar.

El cine era una de las atracciones principales. En ocasiones, se utilizaba como herramienta educativa; podían ser films de divulgación científica, documentales sobre costumbres de otros países o vistas de paisajes nacionales. A fines de los años 1930, además, la Escuela de Estudios Sociales «Juan B. Justo» y la revista Vida Femenina impulsaron un ciclo de "cine polémico", donde se proyectaban películas con temáticas de actualidad que luego eran analizadas por dirigentes del partido. Sin embargo, la abrumadora mayoría de las proyecciones realizadas en la Casa del Pueblo tenían una finalidad puramente recreativa y pasatista. El cine de Hollywood, en particular, tenía una presencia casi excluyente. Teniendo en cuenta la composición familiar del público, no es de extrañar que las comedias protagonizadas por Buster Keaton, Monty Banks, Ben Turpin, Ralph Graves y Johnny Arthur, fueran las más proyectadas. Pero también había lugar para los dramas, cuyos papeles principales eran encarnados por las mismas estrellas que aparecían en la profusa sección cinematográfica de La Vanguardia desde fines de los años 1920. La música era otro ingrediente fundamental. Además de los himnos obreros y socialistas, sonaban sinfonías de Beethoven, nocturnos de Chopin, serenatas de Schubert y romanzas de Puccini, pero también «aires nacionales», como zambas, cuecas y vidalas. Incluso el tango tuvo su lugar, de la mano de una figura destacada a fines de los años I920, como Carlos Gardel, que cantó «Viejo curda» como

\footnotetext{
14 «Movimiento de libros habido en la Biblioteca Obrera Juan B. Justo (Casa del Pueblo)», LV, 04/02/1940.
} 
preludio a una conferencia de Américo Ghioldi ${ }^{15}$. Con todo, lo más usual era que tanto los músicos como los bailarines, humoristas y declamadores, provinieran de los circuitos más modestos de consagración barrial.

Los festivales siempre se cerraban con un baile musicalizado por una orquesta típica y de jazz. En los años 1930, la ciudad atravesaba una expansión en la oferta de bailes de fin de semana, sobre todo en centros y clubes barriales. En este contexto, los socialistas ofrecían iniciativas bailables en la Casa del Pueblo, como los «té danzantes», organizados por la revista Vida Femenina con el objetivo de recaudar fondos y recibir donaciones para España, de modo similar a los que llevaba adelante la «Junta para la Victoria». En un mundo que se prendía fuego con una guerra devastadora, el baile se presentaba como el ideal del movimiento pacifista, ya que las pulsiones eran canalizadas en un juego que podría ser intenso, pero nunca destructivo (PUJOL, 1999). Durante el carnaval de 1942, las juventudes socialistas convocaban a un baile para la noche del sábado de la siguiente manera:

«Ríase del calor... que pasarán los reaccionarios y demagogos al ser derrotados el I ${ }^{\circ}$ de marzo! En la Terraza de la Casa del Pueblo la temperatura será deliciosa. (...) El ambiente más optimista que usted haya conocido, será el que encontrará en esta fiesta juvenil, animada por la seguridad de un gran triunfo socialista. Decoraciones, flores, luces, música movida, alegría desbordante y fresco, mucho fresco en la amplia terraza ${ }^{16}$.

Se trataba de reflejar un clima optimista que trasladaba las buenas nuevas del cambio en el rumbo de la guerra a las inminentes elecciones locales: en las fotos del baile veraniego, muchas de los jóvenes y las señoritas retratadas formaban la «V» de victoria con sus dedos.

El público femenino era interpelado directamente en estas iniciativas. El Comité Juan A. Luoni organizó varias ediciones de la «Fiesta de la compañera», un homenaje a las mujeres que sabían «elevarse por sobre los prejuicios y cobardías del medio ambiente» ${ }^{17}$. En abril de 193I, por ejemplo, se ofrecía un programa que incluía una conferencia de Alfredo Palacios, la presentación del dúo criollo Mazzei-Candal y la proyección de Micifus en Alaska, un film de dibujos animados

\footnotetext{
15 «Comité Juan A. Luoni», LV, 25/05/1928.

16 LV, 12/02/1942.

17 «El festival de la compañera», LV, 10/04/1931.
} 
para niños. La inclusión de una película infantil evidencia hasta qué punto la interpelación femenina estaba impregnada de un discurso familiarista y maternalista, de allí que estas fiestas organizadas y/u orientadas al público femenino fueran presentadas como instancias de reunión de la "gran familia socialista». Las actividades destinadas específicamente a los niños estaban organizadas por el sector femenino del partido, y constaban de festivales, cursos de educación física en la terraza y excursiones al aire libre.

Finalmente, debe hacerse una mención a la labor social y asistencial de la Casa del Pueblo. En el caso del asesoramiento legal, se trataba de una práctica que venía desde la primera década del siglo. Inicialmente organizado para resolver consultas ligadas a la legislación del trabajo, es posible que su activo funcionamiento en los años I930 se haya extendido a otras facetas del derecho. Así lo parece indicar el hecho de que la persona a cargo de esta iniciativa, el abogado y dirigente Silvio Ruggieri, se destacara en este mismo período como diputado nacional en el tratamiento de cuestiones atinentes a la situación de inferioridad jurídica de las mujeres en el terreno civil y político. En tanto, la Casa del Pueblo contaba con un comedor abierto todos los días desde la mañana hasta la medianoche. Como lo sugiere el menú que publicitaba La Vanguardia, no se orientaba a resolver las necesidades alimentarias de los sectores más vulnerables, como solían hacer los comités radicales de la ciudad. En la casa de los socialistas, el espacio del comedor parece haber jugado un papel de encuentro y conversación en el marco del respeto por ciertas pautas propias de la sociabilidad burguesa: prohibición del alcohol y los juegos de azar, camareros uniformados (que se sentirían «ofendidos» si se le ofrecía propina), disponibilidad de materiales de lectura y exhibición de obras de arte.

\section{SOCIALISTAS EN LA CALLE}

Entre las novedades que aportó la historiografía reciente sobre la vida política de los años 1930, se destaca una mayor atención a las formas de participación ciudadana en la esfera pública. Contra la imagen de apatía y desmovilización que la expresión "década infame» había instalado en los relatos sobre la época, distintos abordajes demostraron la relevancia de las manifestaciones callejeras por parte de actores sociales y políticos diversos: radicales, nacionalistas, católicos, comunistas, conservadores (GONZÁLEZ ALEMÁN, 20I3; LOSADA, 20I7; MAURO, 2OI7). En cuanto 
al socialismo, se ha destacado que en la primera mitad de la década, la voluntad por presentarse como un partido «constructivo» y de «orden» primó sobre las voces que llamaban a tomar la calle (IÑIgo CARrERAS, 2005). No obstante, también ha sido señalado que el ps no se privó de organizar mitines callejeros, y que llegó a incorporar mecanismos de autodefensa que autorizaban un potencial uso de la violencia para repeler los ataques de agrupaciones nacionalistas (GONZÁLEZ ALEMÁN, 2OI3). Con todo, aún no se cuenta con una imagen de conjunto sobre el modo en que los socialistas se vincularon con las prácticas de ocupación del espacio público urbano en los años 1930 y 1940. En este sentido, un análisis del rol que tuvo la Casa del Pueblo en los itinerarios de movilización política del socialismo en la ciudad de Buenos Aires puede aportar elementos para esa reconstrucción. Se trata de una vía productiva de indagación dado que la inauguración de aquella coincidió con un momento de particular intensificación de dichas prácticas, que plantearon una tensión respecto del ideal de ciudadanía «educada» y «civilizada» promovido por la reforma electoral de I9I2.

El bautismo de la Casa del Pueblo como epicentro de la movilización callejera fue un funeral. La muerte del líder y fundador del ps, Juan B. Justo, el 8 de enero de I928 ofreció el marco para una concentración multitudinaria que durante dos días ocupó el interior del edificio y se desbordó largamente hacia la Avenida Rivadavia. Desde muy temprano, la Casa del Pueblo empezó a recibir una gran cantidad de personas interesadas en obtener información que clarificara los rumores sobre el estado de salud de Justo. Y cuando la noticia se confirmó, la que ya era una multitud esperó hasta la noche la llegada de los restos mortales que, por decisión familiar, serían velados en la Casa socialista. En efecto, aunque el presidente del Senado de la Nación había dispuesto lo necesario para llevar a cabo el velorio en la Cámara alta, la nonagenaria madre del difunto autorizó a la cúpula del socialismo a realizarlo en la Casa del Pueblo, ya que su hijo -señaló- «pertenecía» al partido y a sus compañeros ${ }^{18}$.

Las crónicas del rito fúnebre hicieron de la multitud la protagonista excluyente. La Vanguardia describió el «espectáculo imponente e inolvidable» de una muchedumbre atravesada por sentimientos de "congoja», "hondo recogimiento", «angustia» e «intenso dolor colectivo». El orden, el silencio y los rostros adustos fueron la tónica en el comportamiento de la multitud, y el diario socialista dejó en claro que «un hombre como Juan B. Justo no se honra vertiendo lágrimas sobre

18 «La madre de Justo», LV, 09/01/1928. 
su féretro» ${ }^{19}$. No obstante, ni el llanto ante el féretro ni los gritos y empujones en la calle estuvieron ausentes. En las crónicas, la dimensión emocional apareció casi siempre vinculada a la importante participación de mujeres, de niños y de ancianos, que se mostraban menos proclives a contener las lágrimas, como así también a la presencia de grupos juveniles, que hicieron del cortejo callejero un acto con tonos algo más exaltados.

La multitud que desfiló esos días por la Casa del Pueblo era marcadamente heterogénea, en la que «el viejo alterna[ba] con el joven, la mujer con el hombre, el cuello almidonado con el pañuelo» ${ }^{20}$. Según La Vanguardia, no se trataba del "pueblo socialista», sino del "pueblo de la capital de la república [que] ha ratificado, sobre el féretro de Juan B. Justo, su fama de ciudad progresista y liberal» ${ }^{21}$. Por un lado, la realización del rito en la Casa del Pueblo, y no en el Senado, configuraba un espacio de neto carácter partidario. Pero, por otro lado, las crónicas de la prensa describían una multitud de contornos amplios que excedían los límites del partido; «nunca tan casa del pueblo como en estos instantes», dirá el diario Critica en su cobertura ${ }^{22}$.

En efecto, el funeral de Justo, en tanto acontecimiento político en la era de la democracia ampliada, cumplió una doble función de integración y de exclusión (GAYOL, 20I3: 239). Ello se expresó en la disputa con los miembros del PSI, quienes hasta hacía unos meses habían formado parte del partido de Justo, y tras la ruptura seguían reconociendo en él a una figura merecedora de homenaje. Si bien habían cumplido un papel destacadísimo en el proceso de construcción de la Casa del Pueblo, los dirigentes del PSI tuvieron vedada la entrada al edificio para despedir a Justo. El diario Crítica, en esos momentos aliado del nuevo partido conducido por De Tomaso, describió «rencillas alrededor del cadáver» y un «premeditado espíritu de violencia», que terminó «arrebatándole» a los independientes el «derecho legítimo» de participar de la ceremonia. La actitud parecía aún más enervante por cuanto se hicieron presentes en la Casa del Pueblo y en el cementerio de la Chacarita destacados dirigentes del radicalismo y del conservadurismo.

\footnotetext{
19 «Hora de recogimiento», $L V, 09 / 01 / 1928$.

20 «Políticos, estudiantes, obreros, mujeres y niños Ilenan la Casa del Pueblo», Crítica, 09/01/1928.

${ }^{21}$ «Juan B. Justo. El sepelio del inolvidable y fuerte luchador socialista ha resultado una grandiosa apoteosis de su vida y de su obra», LV, 10/01/1928.

22 «Políticos, estudiantes, obreros, mujeres y niños Ilenan la Casa del Pueblo», Crítica, 09/01/1928.
} 
En el transcurso del cortejo fúnebre que el día 9 partió hacia la Chacarita un incidente canalizó las tensiones acumuladas. Según denunció Crítica, un grupo de afiliados al PSI fue atacado a golpes por jóvenes «repettistas» en el momento en que intentaban sumarse a la procesión, y fue despojado de la bandera del Centro Socialista de la sección $5^{\mathrm{a}}$ al que habían pertenecido antes de la división partidaria. La Vanguardia, por su parte, lejos de desmentir el «incidente de la bandera», explicó que quienes habían intentado sumarse a la movilización habían realizado gestos provocativos, lo que obligó a jóvenes socialistas a sacarlos de la columna y recuperar la bandera. El diario socialista felicitó a sus militantes por haber hecho justicia a los golpes y cachetazos, que alcanzaron a un diputado nacional que los acompańaba. Si los comportamientos en el espacio público eran indicadores de la cultura cívica, el episodio muestra un modo de incorporación del socialismo a las prácticas de ocupación política de la calle mucho menos «civilizado» y «educado» de lo que sus propios voceros solían proyectar.

Durante los años I930 y la primera mitad de los de 1940, el socialismo organizó movilizaciones que alcanzaron una concurrencia multitudinaria. El mayor acercamiento que el ps realizó en este período con otras fuerzas consideradas «liberales y democráticas» -empezando por la alianza electoral con el Partido Demócrata Progresista (PDP) en I93I, pasando por los intentos de formación de un Frente Popular en 1936 y culminando en la integración de la Unión Democrática en I945/6- tuvo su correlato en las manifestaciones públicas en las que participó el socialismo. Organizadas en forma conjunta con sectores políticos y sociales, no obstante, estos actos tuvieron a la Casa del Pueblo como una instancia clave en el itinerario. El año 1936 resulta de particular interés para observar este fenómeno. Tanto el acto por el $\mathrm{I}^{\mathrm{o}}$ de Mayo convocado por la CGT, como el homenaje a Roque Sáenz Peña realizado a fines de agosto, tuvieron entre sus animadores a los principales partidos políticos opositores ${ }^{23}$. Los dos actos, realizados en la Avenida Diagonal Norte a pocos metros de la Plaza de Mayo, tuvieron como oradores a representantes de la UCR, del PDP y del ps (el acto por el I ${ }^{\circ}$ de Mayo también incluyó a oradores de la CGT y del Partido Comunista). En ambos la Casa del Pueblo fue el punto de partida del desfile, donde se reunieron los principales dirigentes que

${ }^{23}$ «Una inmensa multitud reafirmó los anhelos de paz, de libertad y de justicia social del pueblo argentino», $L V, 02 / 05 / 1936$; «Una categórica afirmación democrática fue el imponente homenaje popular a Sáenz Peña», LV, 23/08/1936. 
convocaban, como Lisandro de la Torre, José Domenech, Arturo Frondizi y Julio Noble en el acto del Io de Mayo; y Marcelo T. de Alvear, Honorio Pueyrredón y nuevamente Lisandro de la Torre y Julio Noble, en el homenaje a Sáenz Peña. Luego de congregarse en el local socialista, estos dirigentes se ponían al frente de la columna, junto con la primera plana del Ps.

La Casa del Pueblo fue, además, el eslabón fundamental de las movilizaciones del ps en tiempos electorales. La campaña para las elecciones legislativas de marzo de 1942 ofrece un buen ejemplo. Convertido en el portavoz de la causa aliadófila y antifascista, el socialismo obtuvo una gran visibilidad en sus actividades proselitistas. A diferencia de las movilizaciones de 1936, no hubo convergencia con el resto de las fuerzas políticas opositoras. Con una retórica focalizada en denuncias de corrupción, el ps se desmarcó por igual de conservadores y radicales. Volcado a captar el voto «independiente» mediante una defensa de los valores democráticos y liberales, los socialistas obtuvieron en la Capital Federal un importante triunfo, al vencer al radicalismo por primera vez desde 1924 (MARTínez MAZZOLA, 20I7: IO4-IO5).

Aún en plena vigencia del estado de sitio (decretado en diciembre de 194I), los socialistas no escatimaron esfuerzos para hacerse ver en las calles de Buenos Aires. La campaña se desarrolló en diferentes puntos de la ciudad, pero los momentos centrales de la movilización electoral -proclamación de candidatos y cierre de campaña-, se efectuaron sobre el frente de la Casa del Pueblo, tras un desfile por Avenida Rivadavia iniciado en la Plaza del Once.

Las crónicas de estos actos revelan dos rostros diferentes y aparentemente contradictorios de la movilización callejera. Uno, es aquel que refuerza la amplitud de la convocatoria, la heterogeneidad de los participantes y la espontaneidad de su motivación. Vinculado al interés del socialismo por salir al encuentro del electorado «consciente y democrático» de la ciudad, este rostro aparece con fuerza en las crónicas de La Vanguardia, donde podía leerse lo siguiente: «La masa popular porteńa, tantas veces defraudada y engañada por los profesionales de la politiquería criolla, acudió al llamado de nuestro viejo y glorioso Partido, como a una cita de honor y argentinidad, espontánea y libremente, sin claques reclutadas, movilizaciones 〈administrativas», presiones «superiores», ni anzuelos electorales» ${ }^{24}$. Frente a una imagen de multitudes manipuladas, los socialistas hablaban de una muchedumbre «amalgamada por ideales, emociones y propósitos de alto sentido nacional».

24 «Magnífica Proclamación de los candidatos socialistas», LV, 08/02/1942 
No obstante, esta imagen se veía contrapesada por un elemento que caracterizó a las movilizaciones de 1942, y que fue resaltada no sólo por La Vanguardia sino también por parte de la prensa porteña: el protagonismo de las Juventudes Socialistas ${ }^{25}$. En efecto, la «formación juvenil» que encabezó los desfiles logró diferenciarse de la «densa masa uniforme» y atraer la atención por sus movimientos pautados, sus vestimentas distintivas, sus antorchas, gallardetes y estandartes, $\mathrm{y}$ sus cantos coordinados. Alineados en escuadras de a cuatro, los jóvenes de ambos sexos (más de mil en el acto de cierre) mostraban una asombrosa precisión y limpieza en la ejecución de sus movimientos, que realizaban según las instrucciones de sus directores y comisarios.

La participación juvenil incorporaba un matiz relevante a la imagen de la convocatoria heterogénea y espontánea, dado que suponía una disciplinada organización partidaria. El peso que tuvo esta faceta de la movilización se puede vincular a la decisión de presentar al partido como única opción posible frente a la «politiquería criolla» encarnada en el resto de los partidos. Mientras que los radicales habían decidido suspender sus actos en protesta por la aplicación del estado de sitio, los socialistas buscaron redoblar su presencia en las calles con muestras de disciplina organizativa. Al mismo tiempo, el tipo de participación juvenil que se observó en los actos de 1942 le daba al partido la posibilidad de desplegar elementos rituales y simbólicos, de forma similar a las movilizaciones de la juventud socialdemócrata europea en los años de entreguerras (MOSSE, [1974] 2005: 222-223). En este sentido, el momento culminante del despliegue juvenil adquirió un fuerte carácter litúrgico y permitió reunir las dos facetas aparentemente contradictorias de sus movilizaciones - la espontaneidad popular y la disciplina partidaria-. Al llegar al frente de la Casa del Pueblo, la formación juvenil entonó las estrofas del himno nacional, que realizó, con «giros viriles y vibrantes», junto a la multitud presente. Según La Vanguardia, los primeros acordes de la canción patria se hicieron oír en medio de un «silencio religioso». Y cuando se cerró la última nota de la introducción, «la afirmación tres veces repetida de libertad, como una imprecación, se elevó vibrante al cielo de la capital argentina, dándole contenido emocional y el valor que le atribuyeron los hombres de Mayo» ${ }^{26}$. En esta multitud, insistía el cronista,

\footnotetext{
25 «Destacan los diarios la excepcional magnitud del mitin socialista», LV, 09/02/1942

26 «Magnífica proclamación de los candidatos socialistas», LV, 08/02/1942.
} 
no había mercenarios ni reclutados, sino los «hombres libres» que acompañan al movimiento socialista ${ }^{27}$

En la campaña electoral de comienzos de 1946, esta duplicidad observada entre la espontaneidad ciudadana y la disciplina organizativa se resolvió en favor de la primera. Ello debe comprenderse en relación al contexto dictatorial, que condujo al PS a confluir con la UCR, el PC y el PDP en la Unión Democrática (que sostenía la candidatura presidencial Tamborini-Mosca); pero, sobre todo, al impacto que tuvieron las movilizaciones del 17 de octubre de 1945 y las subsiguientes manifestaciones de apoyo a la candidatura oficialista de Perón. El socialismo había interpretado esas movilizaciones como el producto de una «estrategia aprendida en los cursos de cultura fascista», donde los abrazos, los gritos y los vítores formaban parte de un plan premeditado, diseñado militarmente y llevado a cabo con apoyo policial. Frente a la «fabricación» de las manifestaciones peronistas, el socialismo buscó exhibir el «espectáculo reconfortante de la espontaneidad». Así, en la crónica de la proclamación de candidatos del ps a legisladores nacionales realizada el 2 de febrero frente a la Casa del Pueblo La Vanguardia no se detuvo en los contornos socialistas del acto, y la describió, en cambio, como una «jornada patriótica, alto exponente del sentir de nuestro pueblo que, haciendo olvido de sus diferencias políticas, ha mancomunado sus esfuerzos en el supremo intento de derribar la tiranía». En su caracterización del mitin, el periódico socialista se deshizo en halagos a la espontaneidad de los "públicos convocados por y para la libertad», y la contrapuso al automatismo y artificiosidad de los «rebaños» oficialistas «que ríen o lloran, aplauden o callan a lo instantáneo de una orden o al apretar de un botón».

Como nunca, la crónica de esta movilización destacó el protagonismo de la muchedumbre congregada sobre la Casa del Pueblo. No hubo en este caso descripciones pormenorizadas, sino una insistencia en el fervor y la vehemencia de la difusa multitud que «negreó» la Avenida Rivadavia. Según La Vanguardia, esta masa exultante y efusiva, al grito de «Venceremos» y «No pasarán», fue incluso capaz de dictar esa noche el sentido de las alocuciones de los dirigentes. Según el cronista, los «oradores de nota» del ps (entre ellos, Nicolás Repetto, Alfredo Palacios y Américo Ghioldi) debieron dejar de lado la enumeración de problemas y el esbozo de soluciones, y en cambio optaron por traducir las expectativas y los

27 «La Canción Patria», LV, 08/02/1942. 
«estados emocionales» del público. Por primera vez ubicados en el balcón principal de la Casa del Pueblo (hasta entonces, se había erigido un escenario sobre la vereda), estos dirigentes quedaron opacados por el público, que «dio también su discurso y fue un orador más, compendio a su vez de todos los otros porque captó, interpretó y resumió con acierto un conjunto de estados emocionales que son la expresión más alta de esta lucha en defensa del tipo de vida democrático» ${ }^{28}$.

\section{CIERRE}

El 27 de agosto de 1947, inspectores de la Municipalidad se presentaron en los talleres de la Sociedad Editora «La Vanguardia» y, luego de comprobar que las instalaciones carecían de sala de primeros auxilios y de señalar que la descarga de bobinas en la vereda de la Avenida Rivadavia causaba ruidos molestos, procedieron a su clausura ${ }^{29}$. El decreto de cierre sine die firmado por el intendente culminaba una escalada de tensión entre el ps y el gobierno peronista y le daba un significativo golpe a las posibilidades de acción al socialismo. Tras quedarse en 1946 sin representación parlamentaria (por primera vez desde 1912), el cierre de los talleres condenó a La Vanguardia, que tiraba entonces alrededor de 300.000 ejemplares por semana, a una existencia clandestina y raquítica de la que no se recuperaría nunca. Pero no sólo eso. Durante la dictadura militar, en cinco ocasiones el periódico La Vanguardia había sido obligado a interrumpir su publicación, por sus recurrentes críticas al gobierno. Sin embargo, en ningún caso se habían clausurado las instalaciones donde se imprimía el principal vocero partidario y numerosos periódicos, revistas y folletos. Impedida de realizar cualquier actividad periodística y editorial, la Casa del Pueblo perdió en 1947 buena parte de la vitalidad que había mostrado en sus dos décadas de existencia. La clausura de las instalaciones de redacción e imprenta de la Casa del Pueblo quitaron una buena parte de su razón de ser al gran local socialista.

${ }^{28}$ Las referencias, en: «Un anticipo del triunfo fue el acto del sábado», $L V, 05 / 02 / 1946$.

29 "Clausuran el taller de La Vanguardia», Clarín, 28/8/1947; «La municipalidad clausuró la imprenta de La Vanguardia», La Prensa, 28/08/1947. 
El cierre de los talleres de La Vanguardia fue un acto puramente burocrático. Ese día la Casa del Pueblo recibió la visita de empleados de Réditos, de la Policía Municipal, de Inspecciones de Pesos y Medidas, de Trabajo y Previsión, de Salud Pública, de la Inspección Nacional de Justicia y del Instituto Nacional de Previsión Social, que buscaban razones que justificaran la clausura. Si se contextualiza este episodio en el proceso más general de ruptura que significó el ascenso del peronismo para el mundo del periodismo, resulta tentador contraponerlo con el acontecimiento que señaló un antes y un después en la historia de Crítica. Casi dos años antes, pasada la medianoche del I7 de octubre de I945, su edificio de Avenida de Mayo fue atacado con armas de fuego y bombas molotov por algunos de los manifestantes que antes habían vivado a Perón en la Plaza de Mayo. El asedio, además de un saldo de dos muertos y varios heridos, dejó moribundo al popular vespertino. La magnitud y virulencia del ataque a Crítica expresaba mucho más que una reacción ante el reciente discurso antiperonista del vespertino. Se trataba del reconocimiento de la «traición» de Crítica hacia el papel de genuino representante de las masas populares que había encarnado en el pasado. La violencia del acontecimiento podría leerse como fruto del choque entre la emergente sensibilidad populista del peronismo y el giro opositor de un actor reconocido por su capacidad para expresar demandas populares (CANE, 2OI2: I69). Por el contrario, podría argumentarse, el procedimiento frío y burocrático llevado a cabo contra La Vanguardia en 1947 puso de relieve la brecha, referida por Daniel James, entre la brutal eficacia de la retórica peronista, de carácter concreto y con una fuerte tonalidad plebeya, y una cultura política de izquierda saturada de pedagogismo moralizante y desconfiada de los hábitos y valores de las mayorías trabajadoras (JAMES, I990).

No obstante, esta dicotomía debería ser matizada. Tal como este artículo ha puesto de relieve, las actividades desarrolladas en la Casa del Pueblo hablan de una cultura política de rasgos mucho menos rígidos y normativos de lo que suele admitirse cuando se la coloca frente a la emergente sensibilidad populista. Si se lo mira desde la perspectiva de la "crisis peronista» del socialismo, se corre el riesgo de sobredimensionar el peso de la concepción de su rol educador, fuertemente desconfiado de la espontaneidad popular, y de configurar retrospectivamente una imagen parcial e incompleta de la forma que asumieron sus prácticas de sociabilidad cultural y movilización política en las décadas previas. El dinamismo de la Casa del Pueblo en los años 1930 y 1940 se sostenía, en una parte importante, en una oferta cultural centrada en lo lúdico y lo festivo, que incorporaba medios y len- 
guajes expresivos novedosos vinculados a las nuevas industrias del entretenimiento. Aunque las reflexiones y sistematizaciones de los dirigentes acerca de las metas de la sociabilidad cultural del ps nunca se alejaron de la tradicional concepción tutelar, las convocatorias y las prácticas efectivas en este terreno mostraban una clara sintonía con las formas de recreación y entretenimiento popular de la sociedad de masas. Si bien requeriría un examen más detallado, de lógicas específicas y matices, no resulta aventurado sugerir que el aporte del socialismo fue fundamental en el proceso más general de confluencia entre sociabilidad cultural, entretenimiento y política que caracterizó a los años 1930.

A su vez, en el examen de las formas de movilización callejera del socialismo en estos años se vislumbran tensiones entre el ideal de ciudadanía culta y civilizada, expresado en la búsqueda de una ocupación ordenada y disciplinada de espacio público, y las novedades que conllevaba el protagonismo de la multitud congregada en las calles con fines políticos. El socialismo tuvo una incidencia importante en la creciente presencia de las masas en la vía pública e hizo de su Casa del Pueblo un punto estratégico en el itinerario de movilizaciones que incorporaban a sectores sociales y políticos que excedían los límites partidarios. El protagonismo juvenil, la dimensión litúrgica con fuerte contenido emocional, e incluso la irrupción episódica de la violencia, formaron parte del despliegue callejero que, con distintos fines y en coyunturas políticas cambiantes, el socialismo realizó en torno de la Casa del Pueblo de Buenos Aires.

\section{Referencias bibliográficas}

XXI CONGRESO ORDINARIO DEL PARTIDO SOCIALISTA (1932), s/d.

BALLENT, ANAHÍ (2014): «Socialismo, vivienda y ciudad. La cooperativa El Hogar Obrero», en: A. Ballent y F. Liernur, La casa y la multitud. Vivienda, política y cultura en la Argentina moderna, Buenos Aires, Fondo de Cultura Económica.

BARRANCOS, DORA (1991): Educación, cultura y trabajadores (1890-1930), Buenos Aires, CEAL. BISSO, ANDRÉS (2009): Sociabilidad, política y movilización. Cuatro recorridos bonaerenses (1932 -1943), Buenos Aires, CeDInCl.

Architecture pour le people. Maisons du people, Brussels, AAM Editions.

BUONUOME, JUAN (2015): «Fisonomía de un semanario socialista: La Vanguardia, 1894-1905», en: Archivos de historia del movimiento obrero y la izquierda, nº.

BUONUOME, JUAN (2016): «Socialismo y prensa en la Argentina. La Vanguardia (1894-1919)», en: L. Jeifets, V. Jeifets y M. Urrego (coords.), Izquierdas, movimientos sociales y cultura política en América Latina, Morelia, Universidad Michoacana de San Nicolás de Hidalgo.

BRAUMAN, ANNICK Y MAURICE CULOT (eds.) (1984): BUONUOME, JUAN (2017): «Periodismo y militancia 
socialista en Buenos Aires a fines del siglo XIX», en: Izquierdas, $\mathrm{n}^{\circ} 37$.

CANE, JAMES (2012): The Fourth Enemy: Journalism and Power in the Making of Peronist Argentina (1930-1955), University Park, Penn State University Press.

COSSART, PAULA Y TALPIN, JULIEN (2012): «Les Maisons du Peuple comme espaces de politisation», en: Revue française de science politique, $\mathrm{n}^{\circ} 4$, vol. 62. DE LUIS MARTÍN, FRANCISCO Y GONZÁLEZ ARIAS, LUIS (2009): Casas del Pueblo y Centros Obreros socialistas en España, Madrid, Pablo Iglesias.

DE PRIVITELLIO, LUCIANO (2003): Vecinos y ciudadanos. Política y sociedad en Buenos Aires de entreguerras, Buenos Aires, Siglo XXI.

DELHAYE, JEAN (1987): La Maison du Peuple de Victor Horta, Bruselas, Atelier Vokaer.

GAYOL, SANDRA (2013): "Ritual fúnebre y movilización política en la Argentina de los años treinta», en: Polhis, no 12.

GIMÉNEZ, ÁNGEL (1932): Nuestras Bibliotecas Obreras. Notas, observaciones, sugestiones, Buenos Aires, La Vanguardia.

GÓMEZ, HERNÁN (2008): «Los diarios como espacios públicos. La Prensa en la vida social de Buenos Aires a comienzos del siglo XX», en: Intersecciones en Antropología, $\mathrm{n}^{\circ} 9$.

GONZÁLEZ ALEMÁN, MARIANNE (2013): «La política al borde del enfrentamiento: violencia y cultura de la movilización en Buenos Aires (1932-1934)», en: HIb: Revista de Historia Iberoamericana, $\mathrm{n}^{\circ} 1$, vol. 6.

GUIAMET, JAVIER (2017): Tentaciones y prevenciones frente a la cultura de masas. Los socialistas argentinos en el período de entreguerras, Tesis de Doctorado, UNLP.

HERRERA, CARLOS (2016): ¿Adiós al proletariado? El Partido Socialista bajo el peronismo (19451955), Buenos Aires, Imago Mundi
IÑIGO CARRERAS, NICOLÁS (2005): «La clase obrera y la alternativa parlamentaria (1932-1936)», en: $\mathrm{H}$. Camarero y C. Herrera (eds.), El Partido Socialista en la Argentina. Sociedad, política e ideas a través de un siglo, Buenos Aires, Prometeo. JAMES, DANIEL (1990): Resistencia e integración. El peronismo y la clase trabajadora argentina, 1946-1976, Buenos Aires, Sudamericana.

KOHN, MARGARET (2001): «The Power of Space: The House of the People as Counterpublic», en: Polity, $n^{\circ} 4$, vol. 33.

LOSADA, LEANDRO (comp.) (2017): Política y vida pública. Argentina (1930-1943), Buenos Aires, Imago Mundi.

MARTínEZ MAZZOLA, RICARDO (2017): «EI Partido Socialista en los años treinta», en: L. Losada (comp.), Política y vida pública. Argentina (19301943), Buenos Aires, Imago Mundi.

MAURO, DIEG0 (2017): «Multitudes católicas, sociedad de masas y política en la Argentina. Reflexiones a partir del Congreso Eucarístico Nacional de 1940», en: Secuencia, nº 97.

MOSSE, GEORGE ([1974] 2005): La nacionalización de las masas. Simbolismo político y movimientos de masas en Alemania desde las guerras napoleónicas al Tercer Reich, Buenos Aires, Siglo XXI.

PUJOL, SERGIO (1999): Historia del baile: de la milonga a la disco, Buenos Aires, Emecé.

ROJKIND, INÉS (2012): «El gobierno de la calle. Diarios, movilizaciones y política en Buenos Aires del novecientos», en: Secuencia, $n^{\circ} 84$.

ROMÁN, CLAUDIA (2010): «La modernización de la prensa periódica entre La Patria Argentina (1879) y Caras y Caretas (1898)», en: A. Laera (dir.), Historia crítica de la literatura argentina, vol 3: El brote de los géneros, Buenos Aires, Emecé. SAÍTTA, SYLVIA (1998): Regueros de tinta. El diario Crítica en la década de 1920, Buenos Aires, Sudamericana. 